\title{
Structural Properties and Testing of a Composite Banding Used in High-speed Rotors
}

\author{
V. Lelos, S.M. Manifold, and J.J. Granier \\ Center for Electromechanics \\ The University of Texas at Austin
}

\begin{abstract}
The use of high strength structural composite bandings is essential for high-speed rotors. In addition to bandings designed for maximum stiffness and strength, there is also a need for bandings that exhibit a controlled radial growth during operation. Controlling the radial growth rate of rotor bandings to match the growth of other rotor components maximizes the structural integrity of the rotor by minimizing reaction forces between parts during operation. This paper presents the structural material properties and strain- to-failure of a composite banding built with a layup consisting of high strength IM7 hoop filament windings and a combination of T700 tape laid at $0^{\circ}$ and $\pm 45^{\circ}$. The analysis and structural test results used to determine the strength of a composite banding with the non-traditional 100\% hoop wound layup is discussed in this paper.
\end{abstract}

\section{INTRODUCTION}

The demand for high speed, light-weight generators, flywheels, and other rotating machines has led to advancements in the field of composite materials. The use of high-strength and high-stiffness composite bandings has been essential for highspeed applications in limiting radial growth and managing centrifugal loads.

Some composite rings within a rotor have a different design criterion, however, in that they must be designed to have a specific stiffness (stiffness per unit mass) dictated by other rotor components. In general, these rings are designed not for maximum strength, but for a target stiffness, and they must be capable of undergoing hoop strain controlled by other rotor components. The target stiffness must be achieved so that the rings do not exert large interface stresses on adjacent rotor components. 
The radial growth of a composite banding can be modified by varying its stiffness in the hoop direction without significantly lowering the strain capability of the material. Hoop stiffness in composite bandings can be varied by incorporating fibers wound at angles other than $90^{\circ}$. The strain capability of the composite would be modified as the layup is modified to achieve the desired hoop characteristics, and experimental testing is required to determine the strain-at-failure of the material.

\section{SAMPLE DESIGN}

Typically, outer composite bandings of rotors are designed for maximum strength and stiffness and are constructed with $90 \%$ or more of fibers wound in the hoop direction. These fibers maximize the hoop strength and stiffness of the banding, thus limiting spin growth of the rotor. Locating composite bandings at an intermediate radius of a rotor creates a challenge in that these bandings must have sufficient strain capability, but they may also be required to undergo spin growth at a rate dictated by other rotor components. These requirements lead to the design of high-strain composite rings with tailored specific hoop stiffness. A layup that consists of IM7 hoop windings and a combination of T700 tape laid at $0^{\circ}$ and $\pm 45^{\circ}$ was used to modify the hoop stiffness of the banding to the desired level. Two composite matrix materials (Table 1 ) were designed and fabricated.

In order to model the banding accurately in a rotor finite element model, its orthotropic laminate stiffnesses had to be determined. These stiffnesses were based on classical 3D stress-strain relations and a rule of mixtures formulation for orthotropic materials, with lamina properties transformed according to winding angle. [1].

The strain-at-failure and the laminate hoop stiffness of the banding were experimentally determined (table 2) using a hydroburst test procedure.

TABLE 1. COMPOSITE MATRIX MATERIALS

\begin{tabular}{|c|c|}
\hline Group A & $\begin{array}{l}\text { 43.5\% IM7/977-2 } 90^{\circ} \text { ply (Resin content 32\%) } \\
\text { 28.25\% T700/977-2 } \pm 45^{\circ} \text { Tape (Resin content 38\%) } \\
\text { 29.25\% T700/977-2 } 0^{\circ} \text { Tape (Resin content 38\%) }\end{array}$ \\
\hline Group B & $\begin{array}{l}\text { 41.5\% IM7/977-2 } 90^{\circ} \text { ply (Resin content 32\%) } \\
\text { 29.25\% T700/977-2 } \pm 45^{\circ} \text { Tape (Resin content 38\%) } \\
29.25 \% \text { T700/977-2 } 0^{\circ} \text { Tape (Resin content 38\%) }\end{array}$ \\
\hline
\end{tabular}

TABLE 2. PRedicted AND TESTED BANDing CIRCUMFERENTIAL PROPERTIES

\begin{tabular}{|c|c|c|c|}
\hline $\begin{array}{c}\text { Ring } \\
\text { Set }\end{array}$ & $\begin{array}{c}\text { 0 Bleed Enoop } \\
\text { Theoretical } \\
(\mathrm{msi})\end{array}$ & $\begin{array}{c}\text { Tested } \\
\text { Enoop }_{(\mathrm{msi})}\end{array}$ & $\begin{array}{c}E_{\text {hoop }} \\
\text { difference } \\
(\%)\end{array}$ \\
\hline Group A & 12.3 & 12.58 & 2.28 \\
\hline Group B & 11.8 & 11.87 & 0.6 \\
\hline
\end{tabular}




\section{HYDROBURST TEST}

The hydroburst test [2] method was used to determine the ultimate failure strength and strain of coupons made with the candidate layup. In a hydroburst test, a ring-shaped coupon and an inboard seal are captured between two steel platens in the test fixture, as shown in figure 1. Hydrostatic pressure is applied with a hydraulic power supply to create a uniform load on the coupon, which increases until failure occurs. Edge effects can influence the results for this particular layup, due to the short axial length of the test coupons, but edge effects are also present in the actual component and, therefore, do not invalidate the results.

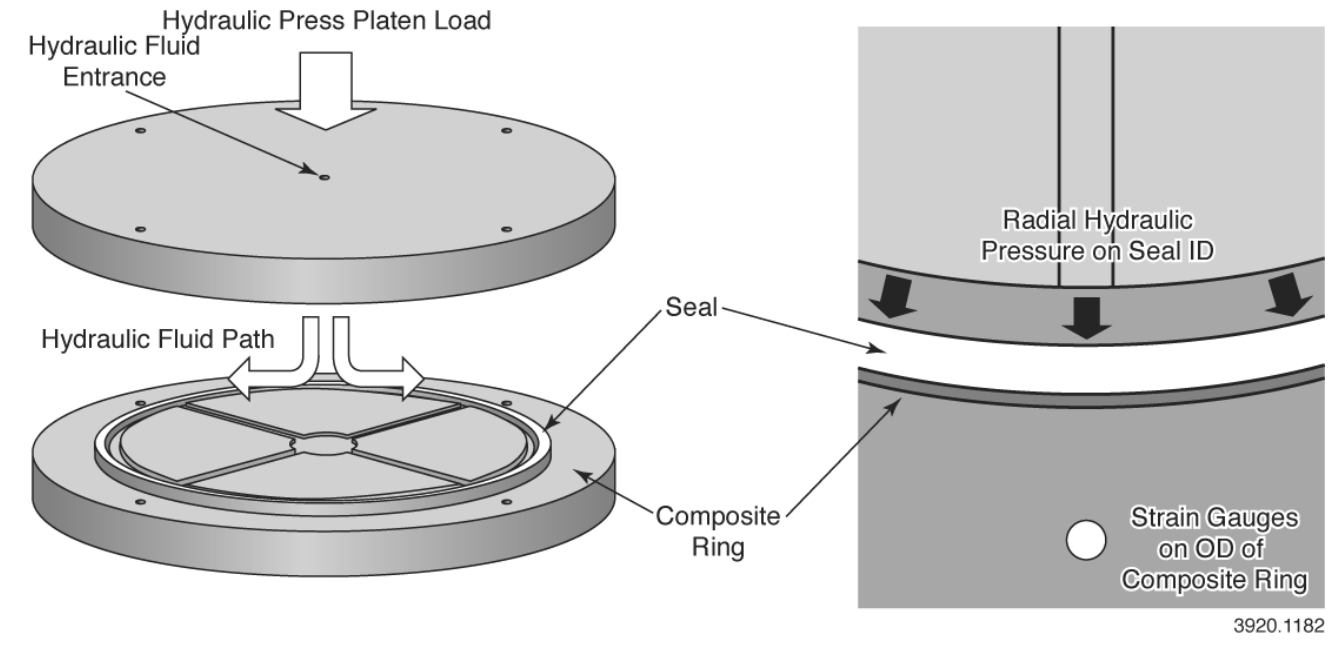

Figure 1. Hydroburst test schematic

The main advantage of hydroburst testing lies in the engineer's ability to verify the operating strength and hoop stiffness of the layup design within a short time frame.

The test coupons were fabricated using a single tow laydown method of IM7 filament windings manufactured from $12 \mathrm{~K}$ carbon fiber tow-preg impregnated with 977-2 resin and a hand-laid T700 tape with the same 977-2 resin. (Hexcel Corporation made the IM7 filament windings; Cytec Engineered Materials made the 977-2 resin.) The coupons were cured in an autoclave at $350^{\circ} \mathrm{F}$, using a zero-bleed bagging method.

Two 10 in. long hydroburst rings were manufactured using slightly different layup designs. The rings were then sectioned into the individual test coupons, providing a group of 14 test coupons each. The ring-shape test coupons had an average internal diameter of 20.093 in., average radial thickness of 0.142 in., and average axial length of 0.487 in.. Two different layup designs were manufactured and tested in order to study the effects of slight variations that might arise during manufacturing on the strength of the composite.

Internal pressure was applied to the test coupons by the expanding seal until failure occurred. The circumferential and axial strain of the rings were measured with strain gauges mounted at the outside diameter of the test coupons. Four gauges were mounted in the circumferential direction $90^{\circ}$ apart, and two gages were mounted next to 
the hoop-oriented gauges in the axial direction $180^{\circ}$ apart. The readings from the strain gauges were digitally recorded during the test along with the internal pressure applied to the seal.

\section{RESULTS}

Pressure vs. strain data was collected for each tested coupon. A representative plot of the collected data is shown in figure 2. The yield strain was taken at the point at which the pressure-to-strain curve lost its linearity. This point was considered the point of the first internal failure of the structural integrity (yield or integrity failure) of the coupon. The ultimate hoop strain was the last valid hoop strain recorded by the strain gauges. Since the failure of the coupons was nearly instantaneous, the final recorded strain was the strain-to-failure limit of the coupons (ultimate failure).

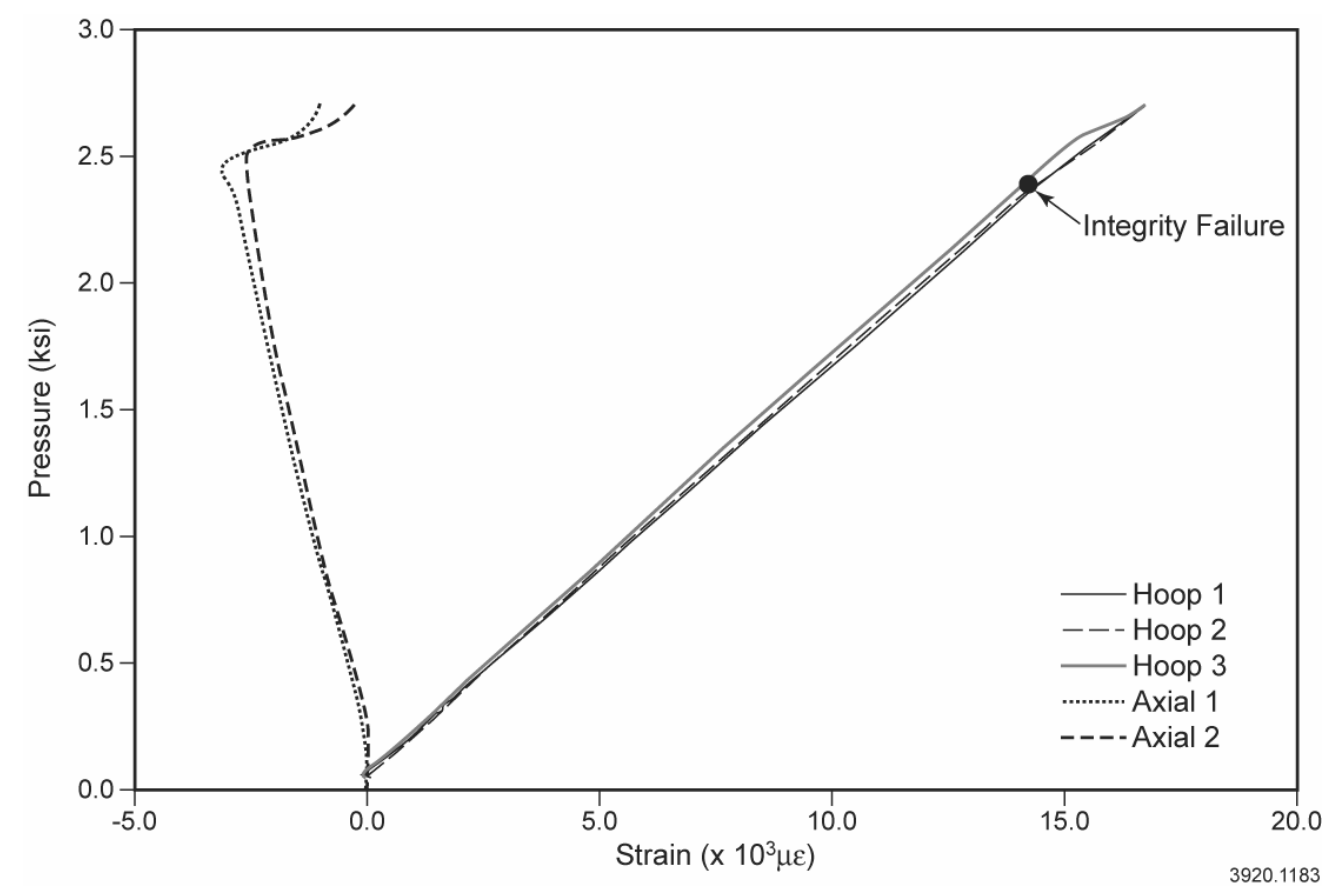

Figure 2. Representative data recorded by five strain gauges and pressure transducer (Group B sample 7)

The approximate strength of the material was calculated, using the coupon geometry and the pressure readings taken during the experiment. The peak hoop laminate strength of the tested rings can be approximated by using the closed form solution for thin-walled cylinder stress due to internal pressure. According to this relationship,

$$
\sigma_{\theta}=\frac{P D_{\mathrm{avg}}}{2 t}
$$


where

$$
\begin{aligned}
\sigma_{\theta} & =\text { hoop stress } \\
P & =\text { inner seal radial pressure } \\
D & =\text { inner diameter of the ring } \\
t & =\text { ring thickness }
\end{aligned}
$$

This approach is appropriate because the thickness to radius ratio $(t / r)$ of the test coupons is less than 0.10 [3].

The hoop modulus of each coupon was calculated by using the calculated hoop stress and the measured hoop strain data (figure 3).

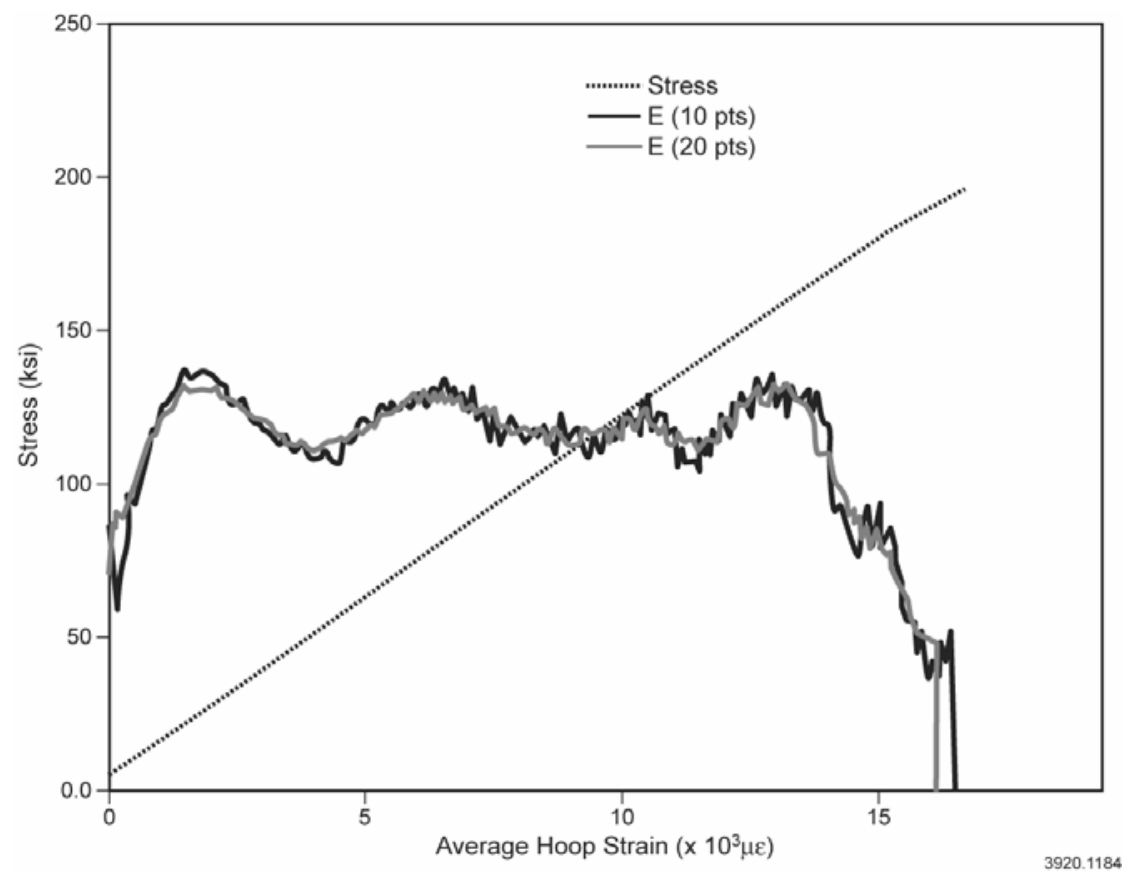

Figure 3. Representative stress-strain plot and a slope approximation used in calculating the hoop modulus $(E)$ plot as a function of the average hoop strain (Group B, sample 7)

The initial modulus (also the chord modulus) shown in tables 3 and 4 was first calculated in accordance with ASTM D3410/D for the data between 1,000 and 3,000 $\mu \varepsilon$. In order to compare the linearity of the stress-strain curve, the slope (finite derivative approximation) of the data curve was calculated between 10 and 20 strain points. The initial hoop modulus values are reported using the average 20 strain point derivative in the linear range, rather than the generic ASTM range. Significant data points and calculated values are shown for both sample groups in tables 3 and 4 . 
TABLE 3. GROUP A EXPERIMENTAL DATA AND CALCULATED RESULTS

\begin{tabular}{|c|c|c|c|c|c|c|c|}
\hline Ring No. & $\begin{array}{c}\text { Peak } \\
\text { Linear } \\
\text { Pressure } \\
\text { psi }\end{array}$ & $\begin{array}{c}\text { Peak } \\
\text { Ultimate } \\
\text { Pressure } \\
\text { psi }\end{array}$ & $\begin{array}{l}\text { Peak } \\
\text { Linear } \\
\text { Strain - } \\
\text { Hoop } \\
\mu \varepsilon\end{array}$ & $\begin{array}{c}\text { Ultimate } \\
\text { Strain - } \\
\text { Hoop } \\
\mu \varepsilon\end{array}$ & $\begin{array}{l}\text { Peak } \\
\text { Linear } \\
\text { Hoop } \\
\text { Strength } \\
\text { ksi }\end{array}$ & $\begin{array}{l}\text { Ultimate } \\
\text { Hoop } \\
\text { Strength } \\
\text { ksi }\end{array}$ & $\begin{array}{c}\text { Initial } \\
\text { Hoop } \\
\text { Modulus } \\
\text { msi }\end{array}$ \\
\hline 1 & 2,533 & 2,796 & $14,286.0$ & $15,991.3$ & 180.13 & 199.17 & 12.49 \\
\hline 2 & 2,742 & 2,742 & $11,435.0$ & $11,435.0$ & 194.44 & 194.44 & $19.14^{*}$ \\
\hline 3 & 2,463 & 2,538 & $13,650.0$ & $14,079.3$ & 175.04 & 175.04 & 12.57 \\
\hline 4 & 2,632 & 2,745 & $14,499.0$ & $15,198.0$ & 187.21 & 195.38 & 12.87 \\
\hline 5 & 2,535 & 2,707 & $14,114.7$ & $15,275.0$ & 180.24 & 192.69 & 12.59 \\
\hline 6 & 2,598 & 2,768 & $14,329.0$ & $15,599.0$ & 184.76 & 197.10 & 12.66 \\
\hline 7 & 2,643 & 2,745 & $14,609.7$ & $15,407.7$ & 188.01 & 195.42 & 12.65 \\
\hline 8 & \multicolumn{7}{|c|}{ Not Hydroburst Tested } \\
\hline 9 & 2,603 & 2,686 & $14,473.7$ & $15,040.3$ & 185.14 & 191.15 & 12.54 \\
\hline 10 & 2,691 & 2,814 & $14,944.3$ & $15,971.0$ & 191.49 & 200.45 & 12.52 \\
\hline 11 & 2,610 & 2,720 & $14,635.3$ & $15,486.3$ & 185.67 & 193.66 & 12.54 \\
\hline 12 & 2,540 & 2,884 & $14,111.0$ & $16,461.7$ & 180.60 & 205.53 & 12.48 \\
\hline 13 & 2,250 & 2,608 & $12,634.0$ & $14,693.0$ & 159.75 & 185.54 & 12.47 \\
\hline 14 & $2,657.0$ & $2,800.0$ & $14,993.3$ & $15,979.7$ & 189.08 & 199.45 & 12.58 \\
\hline Avg & 2562.92 & 2734.25 & $14,273.33$ & 15431.86 & 182.26 & 194.22 & 12.58 \\
\hline Std Dev & 117.39 & 93.43 & 634.94 & 646.92 & 8.45 & 7.89 & 0.11 \\
\hline Std Dev \% & 4.58 & 3.42 & 4.45 & 4.19 & 4.64 & 4.06 & 0.87 \\
\hline
\end{tabular}

* Anomaly data not factored into averaged or standard deviation values

TABLE 4. GROUP B EXPERIMENTAL DATA AND CALCULATED RESULTS

\begin{tabular}{|r|c|c|c|c|c|c|c|}
\hline & $\begin{array}{c}\text { Peak } \\
\text { Linear } \\
\text { Pressure } \\
\text { psi }\end{array}$ & $\begin{array}{c}\text { Peak } \\
\text { Ultimate } \\
\text { Pressure } \\
\text { psi }\end{array}$ & $\begin{array}{c}\text { Peak } \\
\text { Linear } \\
\text { Strain }- \\
\text { Hoop } \\
\mu \varepsilon\end{array}$ & $\begin{array}{c}\text { Ultimate } \\
\text { Strain - } \\
\text { Hoop } \\
\mu \varepsilon\end{array}$ & $\begin{array}{c}\text { Peak } \\
\text { Linear } \\
\text { Hoop } \\
\text { Strength } \\
\text { ksi }\end{array}$ & $\begin{array}{c}\text { Ultimate } \\
\text { Hoop } \\
\text { Strength } \\
\text { ksi }\end{array}$ & $\begin{array}{c}\text { Initial } \\
\text { Hoop } \\
\text { Modulus } \\
\text { msi }\end{array}$ \\
\hline \hline 1 & 2,504 & 2,628 & $15,056.0$ & $15,959.5$ & 181.55 & 190.71 & 11.90 \\
2 & 2,436 & 2,617 & $14,666.0$ & $15,974.5$ & 176.56 & 189.92 & 12.00 \\
3 & 2,381 & 2,558 & $14,334.3$ & $15,738.0$ & 172.51 & 185.59 & 11.91 \\
4 & 2,372 & 2,536 & $14,063.0$ & $15,363.0$ & 171.81 & 183.93 & 11.69 \\
5 & 2,417 & $2,664.0$ & $10,241.0$ & $11,551.0$ & 174.4 & 192.49 & $17.60^{*}$ \\
6 & 2,408 & 2,676 & $14,371.3$ & $16,434.3$ & 174.48 & 194.29 & 11.85 \\
7 & 2,382 & 2,701 & $14,242.0$ & $16,716.0$ & 172.57 & 196.16 & 11.80 \\
8 & & Not Hydroburst Tested & & & & \\
9 & 2,358 & 2,700 & $13,845.0$ & $16,465.3$ & 170.76 & 196.04 & 12.12 \\
10 & 2,333 & 2,504 & $13,806.3$ & $16,299.7$ & 168.95 & 181.78 & 12.15 \\
11 & 2,539 & 2,674 & $14,809.7$ & $15,870.7$ & 184.05 & 194.03 & 11.37 \\
12 & 2,513 & 2,634 & $14,929.7$ & $15,878.0$ & 182.18 & 191.13 & 11.86 \\
13 & 2,334 & 2,631 & $13,817.3$ & $15,830.7$ & 169.02 & 190.91 & 12.12 \\
14 & 2,417 & 2,642 & $14,752.3$ & $16,040.0$ & 175.19 & 191.74 & 11.64 \\
\hline Avg & $2,414.75$ & $2,625.08$ & $14,391.08$ & $16,047.47$ & 174.97 & 190.52 & 11.87 \\
Std Dev & 70.08 & 63.20 & 448.87 & 371.63 & 5.15 & 4.63 & 0.23 \\
Std Dev\% & 2.90 & 2.41 & 3.12 & 2.32 & 2.94 & 2.43 & 1.90 \\
\hline
\end{tabular}

* Anomaly data not factored into averaged or standard deviation values 
As shown from the results tables, the average linear peak hoop strain of the two coupon groups was $1.43 \%$ and $1.44 \%$. The average peak ultimate hoop strain was equal to $1.54 \%$ and $1.60 \%$. The average hoop strength within the linear region of each coupon group was equal to $182 \mathrm{ksi}$ and $175 \mathrm{ksi}$. The linear section hoop modulus was calculated to be equal to $12.58 \mathrm{msi}$ and $11.87 \mathrm{msi}$. The percent standard deviation of the linear peak hoop strain was equal to $4.45 \%$ and $3.12 \%$ for group $\mathrm{A}$ and $\mathrm{B}$ respectively.

\section{DISCUSSION AND CONCLUSIONS}

The hoop linear strain-to-failure values did not vary significantly with minor alterations in the layup. Changing the hoop stiffness by $6 \%$ only changed the linear strain-to-failure by $0.7 \%$. Thus, any minor adjustments during manufacturing to achieve the final design part thickness should not have a significant impact in the failure strain of the composite material. The hoop modulus of the rings was also within $3 \%$ of the predicted values, assuming zero bleed during curing. Even though the hoop modulus was calculated based on approximated stress values and varied within the strain region significantly, as long as the region the modulus was based on had minor variations (near liner region), the values should be accurate to use in a structural analysis.

Engineers at the Center for Electromechanics at The University of Texas at Austin have previously conducted extensive hydroburst testing on samples with composite layup designs consisting of $90 \%$ IM7/977-2 towpreg oriented in the circumferential direction and $10 \%$ axial tape. Based on these hydroburst tests, the hoop strain-to-failure of a hoop wound IM7 outer banding layup is approximately equal to $1.55 \%$ in./in.

By comparing the tested results of the new layup to a traditional outer banding layup, it can be concluded that the reduction in failure strain due to the introduction of fiber laid at $\mathrm{a}+/-45^{\circ}$ angle is insignificant compared to the advantage of achieving a desired hoop stiffness, and maintaining the structural integrity of the rotor.

\section{ACKNOWLEDGMENT}

This research was funded by the U.S. Army and managed by ARDEC, located at Picatinny Arsenal in New Jersey.

\section{REFERENCES}

[1] Mechanics of Composite Materials, Robert M. Jones, HPC, ISBN 0891164901.

[2] R.C. Thompson, T.T. Pak, and B.M. Rech, "Hydroburst test methodology for evaluation of composite structures," 14th Symposium on Composite Materials: Testing and Design (ASTM), Pittsburgh, Pennsylvania, U.S.A., March 11-12, 2002.

[3] Robert C. Juvinall, Engineering Considerations of Stress, Strain, and Strength, McGraw-Hill, New York, NY, 1967. 